\title{
Defense Proteins from Sugarcane Studied by Conventional Biochemical Techniques, Genomics and Proteomics: An Overview
}

\author{
Elena Sánchez-Elordi ${ }^{1}$, Roberto Contreras ${ }^{2}$, Roberto de Armas ${ }^{3}$, Mario César Benito ${ }^{4}$, \\ Rocío Santiago $^{1}$, Carlos Vicente ${ }^{1, *}$, María Estrella Legaz ${ }^{1}$ \\ ${ }^{1}$ Intercellular Communication in Plant Symbiosis Team, Faculty of Biology, Complutense University, Madrid, Spain \\ ${ }^{2}$ Centro Regional de Investigación y Desarrollo Sustentable de Atacama, CRIDESAT-UDA, Universidad de Atacama, Atacama, Chile \\ ${ }^{3}$ Department of Plant Biology, Faculty of Biology, Havana University, Havana, Cuba \\ ${ }^{4}$ Department of Genetics, Physiology and Microbiology, Faculty of Biology, Complutense University, Madrid, Spain
}

\section{Email address:}

cvicente@bio.ucm.es (C. Vicente)

${ }^{*}$ Corresponding author

\section{To cite this article:}

Elena Sánchez-Elordi, Roberto Contreras, Roberto de Armas, Mario César Benito, Rocío Santiago, Carlos Vicente, María Estrella Legaz. Defense Proteins from Sugarcane Studied by Conventional Biochemical Techniques, Genomics and Proteomics: An Overview. American Journal of Plant Biology. Vol. 5, No. 3, 2020, pp. 30-37. doi: 10.11648/j.ajpb.20200503.11

Received: June 6, 2020; Accepted: June 22, 2020; Published: July 13, 2020

\begin{abstract}
Sugarcane is a C4 plant from the NADP-ME family, which performs a double photosynthetic carboxylation. It is a plant specialized in accumulating and storing large amounts of sucrose in the parenchymatous cells of its stalks. Perhaps because of these characteristics, this species shows to be extremely sensitive to a large number of diseases caused by viruses, bacteria, phytoplasmas, fungi, insects and nematodes, as well as to various abiotic stresses. A large number of varieties and cultivars resistant to many of these diseases have been achieved through conventional plant breeding techniques and also through biotechnological applications. In addition to this, the ability of the plant itself to produce pathogen resistance factors has been a field of research that has provided excellent weapons to combat crop-destroying pests This review describes those proteins that are synthesized by the plant as resistance factors against different diseases from the point of view of conventional biochemistry and also with the tools that modern genomics and proteomics provide. Special emphasis has been placed on the study of those proteins aimed at increasing the physical resistance of the plant that hinders the entry of the pathogen as well as those proteins related to the synthesis of bioactive phenols, polysaccharide hydrolysis enzymes, bacteriocins, oxygenases, oxidases and oxido-reductases.
\end{abstract}

Keywords: Defense Proteins, Disease, Genomics, Proteomics, Sugarcane

\section{Introduction}

Sugarcane is one of the most prominent commercial crops in tropical and sub-tropical countries, and is the world's main source of white sugar [1].

Being a C4 plant, its photosynthetic metabolism is marked by the existence of a pyruvate Pi dikinase and two different carboxylating enzymes, PEP carboxylase and Rubisco. Sugarcane has also specialized in the accumulation of sucrose in the parenchymal cells of the stems, so the enzymes of synthesis, transport and accumulation of sucrose play a role of primary importance in the metabolism of this species. Finally, maintenance of the health of a plant of such high economic interest is one of the primary objectives of its growers, so knowledge of the defense mechanisms that the species develops against a high number of pathogens (viruses, bacteria, phytoplasm, fungi, insects, nematodes, etc.) is of paramount importance from both the scientific and economic point of view. 


\section{Defence Proteins Related to Phenols and Lignin Production}

A good number of defense proteins against different pathogens of sugarcane have been identified through their purification and the study of the specific reaction they catalyze. For example, Santiago et al. [2] demonstrated that leaves of two cane varieties, one sensitive (Louisiana 55-5) and the other resistant (Mayarí 55-14) to leaf scald, developed high peroxidase (POX) and phenylalanine ammonium lyase (PAL) activities, both proteins related to the lignification process, when treated with protein elicitors purified from pathogen cells. The increase in these enzymatic activities has been clearly related to the increase in the amount of lignin deposited in xylem, phloem and sclerenchyma, a mechanism of mechanical resistance to the entry of the pathogen [3]. An increase in peroxidase activity has been reported by in cane infected with Colletotrichum falcatum [4], much higher in varieties resistant to the fungus than in those that are shown to be sensitive [5]. Both the PAL enzyme, which produces cinnamic acid, and the peroxidase are considered to be defense proteins since they are involved in lignin synthesis, the former producing the precursor of the monolignols and the latter catalyzing the oxidative polymerization of these monolignols to lignin. The lignification of the plant cell walls constitutes a mechanical barrier that effectively blocks the entry of many pathogens [6, 7].

Cinnamyl alcohol dehydrogenase (CAD) is involved in one of the last steps of monolignol biosynthesis that catalyzes the reduction of cinnamyl aldehyde to cinnamyl alcohol before the incorporation of these monolignols into the lignin polymer. Santiago et al. [8] have examined two different sugarcane cultivars; My 55-14 (resistant to smut) and B 42231 (susceptible to the pathogen) and noted that the resistance to smut is of mechanical nature due to a marked increase in lignin concentration by activation of CAD and SAD.

The enzyme from sugar cane stalks was purified 125 times for CAD activity with an overall yield of $24.05 \%$. However, the remaining SAD activity in each purification step resulted in a 6.44 -fold SAD purification with a $1.44 \%$ recovery. This can be taken as circumstantial evidence that ADC and SAD in sugarcane plants are different proteins [9], as reported by Guo et al. [10] for many other plant species, one of which, $\mathrm{SAD}$, is lost during the ADC purification process.

The production of dimers and trimers from monolignols requires of guidance proteins (DIR proteins), a family of proteins, exclusive of plants, involved in the production of lignins and in responses to the invasion by pathogenic organisms and abiotic stresses. These proteins are responsible for the stereo-selective coupling of monolignol radicals to produce lignan or lignin. In sugarcane, DIR proteins were first described by Casu et al. [11]. Nobile et al. [12] have characterized a series of proteins which participate of importan physiochemical and structural properties of a typical pinoresinol-forming, dirigent protein, such as subcellular localization, N-glycosylation sites, nine predicted $\beta$-strand regions and a homo-trimeric conformation.

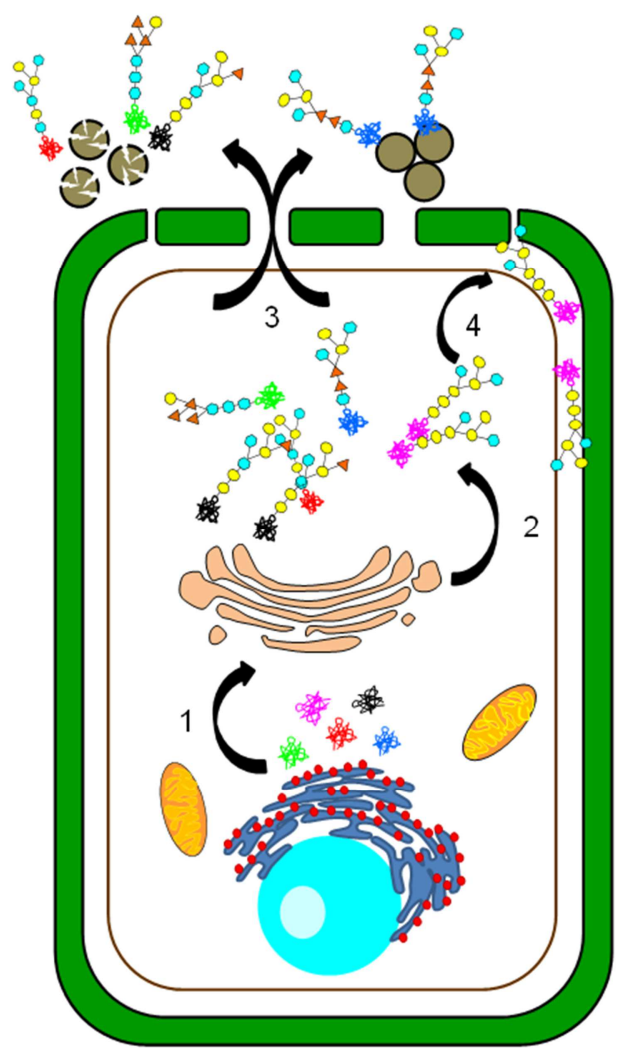

Figure 1. Scheme that represents the synthesis of glycosylated enzymes by a parenchimatous sugar cane cell. Firstly, peptides are synthesized by rough endoplasmic reticulum (RER) (1). Then, they are glycosylated in the Golgi apparatus (GA) (2) and finally released to the media (3) or to the space between the plasma membrane and the cell wall (4). Representing: (), nucleus; $\bigcirc$, mitochondria; signal lectin; chitinase; $\beta$-1,3-glucanase; $\beta$-1,4-glucanase; GA; ; glycosylated DIR protein; lectin; , glycosylated chitinase; glycosylated $\beta$-1,4-glucanase; 8 , agglutinated teliospores; with hydrolyzed cell wall.

\section{Oxidases and Hydrolases}

Catalase, an antioxidant enzyme that catalyzes the breakdown of two $\mathrm{H}_{2} \mathrm{O}_{2}$ molecules into water and oxygen [13]), is induced in sugarcane by an elicitor isolated from $C$. falcatum cells [14] and is synthesized in large quantities in canes inoculated with conidia from the red rot fungus [5].

Polyphenol oxidase is also considered an RP, since it can oxidize different phenols to quinines, substances that are toxic to different microorganisms. The levels of this enzyme in smut resistant sugar canes, infected or not, increased much more than in the corresponding sensitive ones, following a similar behavior pattern to PAL [6].

Sanchez-Elordi et al. [15] detected a set of glycoproteins, the concentration of which increases in smut resistant plants inoculated with teliospores of Sporisorium scitamineum, among which they were able to detect $\beta$-1,3-glucanase, $\beta-1,4-$ glucanase and chitinase activities. Very similar results were obtained by $\mathrm{Su}$ et al. [16] for $\beta$-1,3-glucanase. Previously, 
Santiago et al. [17] had shown that cane varieties highly sensitive to leaf scald greatly increase their $\beta$-1,3-glucanase activity after infection with the pathogen and moderately those varieties with medium sensitivity, while resistant cultivars decrease their $\beta$-1,3-glucanase activity after infection.

A different hydrolase, arginase, an enzyme that hydrolyzes arginine into ornithine and urea, is another glycoprotein currently synthesized by sugarcane plants, whose concentration/activity increases in resistant smut-infected plants [18]. As a resistance protein, it is important to consider that this arginase, secreted by the infected plant, is capable of creating a concentration gradient in the aqueous environment surrounding the plant's organs, binding to specific receptors on the cell wall of the teliospores. The arginase bound to the wall of teliospore can be desorbed with sucrose, which indicates that the glycidic fraction of the enzyme contains $\beta$ 1,2-fructan bonds, active against specific amino acids of the receptor fungal protein [19]. The arginase interaction of plant-teliospore determines the inhibition of the cell polarization of this teliospore, the inhibition of the emergence of the germinative tube and, therefore, the inhibition of the germination (Figure 1). This mechanism is obviously optimally developed in disease-resistant cultivars.

However, this defense mechanism is far more sophisticated than what has been described so far. SanchezElordi et al. [20] were able to find that the smut teliospores themselves, in an aqueous medium, secrete their own arginase which binds to specific wall receptors and from this binding derives the polarization of the actomyosin cytoskeleton, which marks the germinative pore. As the same authors demonstrated using plant arginase labelled with a fluorophore, both plant and fungal arginases use the same cell wall receptors and, in the competition, cane arginase easily displaces the fungal enzyme from the binding sites. The mechanism has thus been defined as a false quorum signal by which the enzyme secreted by the plant chemotactically attracts the fungal spores to the spaces of maximum enzyme concentration [21], displacing the fungal arginase to block its wall receptors and prevent germination.

\section{Other Defense Proteins}

Cystatin, cysteine protease inhibitors have also been described in sugarcane plants [22]. The plant prevents the action of the inhibitor on its own metabolism by inactivating it by dimerization [23]. However, some protease inhibitors produced by the plant cannot be considered sometimes as defense proteins, but quite the opposite. Xanthomonas albilineans produces proteases that selectively hydrolyze UDPG dehydrogenase, an enzyme absolutely required for the production of xanthan. This polysaccharide, unlike what happens with $X$. campestris [24], is only produced when bacteria infect the cane plant and is used to plug the phloem and xylem elements, which induces leaf drying. Blanch et al. [25] demonstrated that sensitive sugarcane cultivars produce, after being infected, glycoproteins that act as inhibitors of these bacterial proteases in such a way that UDPG dehydrogenase remains intact and active and xanthan can be produced. It is likely that this host-pathogenic interdependence is probably derived from a coevolution process. This could explain why $X$. albilineans did not produce xanthans in culture whereas the gum was secreted from bacteria invading sugarcane tissues [26].

\section{Sugarcane Omics Related to Defense Proteins}

Que et al. [27] studied the variation of gene expression of two sugarcane varieties, NCo376 and Ya71-374 after infection with S. scitamineum. Proteins were separated by 2dimensional electrophoresis and identified by MALDI-TOFTOF/MS. In this way, authors describe a cytochrome c peroxidase that catalyzed the reaction:

$$
\begin{gathered}
2 \text { cytochrome c }\left(\mathrm{Fe}^{2+}\right)+\mathrm{H}_{2} \mathrm{O}_{2}+2 \mathrm{H}^{+} \rightarrow 2 \text { cytochrome } \mathrm{c}\left(\mathrm{Fe}^{3+}\right) \\
+2 \mathrm{H}_{2} \mathrm{O}
\end{gathered}
$$

related to the inhibition of the pathogen growth. In addition, Singh et al. [28] identified, by using the same technique, a thioredoxin peroxidase that is upregulated during the first times of smut infection. Other defense proteins differentially expressed after infection were catalase and superoxide dismutase, produced in order to decrease the amount of ROS species related to the disease development.

On the other hand, $\mathrm{Su}$ et al. [29] identified several conventional peroxidase genes by using two different cultivars, resistant and sensitive respectively, and employing an isobaric tag of relative and absolute quatification (ITRAQ) as well as several oxidases and dehydrogenases, some hydrolases, such as $\beta$-1,3-glucanase, endo-1,4- $\beta$-xylanase and an extracellular ribonuclease, two expansins and one lectin. Two different genes of $\beta$-1,3-glucanase, ScGluA1 and ScGluD1, have been described in sugarcane plants. Both genes exhibit a differential expression after inoculation of plants with $S$. scitamineum or under abiotic stress conditions. ScGluA1 was upregulated, whereas ScGluDl was slightly down-regulated, according to $\mathrm{Su}$ et al. [30]. Sugarcane chitinase, another fungal cell wall hydrolytic enzyme, occurred as two different forms, an induced and a constitutive protein. The gene ScChiVIIl codified for the first one and it is differentially expressed in sensitive or resistant cultivars to smut [31] or even to Giberella fujikuroi [32]. The constitutive protein behaves as very active enzyme in resistant cultivars against some pathogen, such as that which produced the red rot disease [33]. Peroxidase was also differentially expressed in sugarcane, the synthesis of which was upregulated after infection with $X$. albilineans. On the other hand, a gene for catalase $(S c C A T 1)$ has been described in sugarcane plants, the expression of which increased after smut inoculation [34]. This fact suggests that the pathogen increases the level of ROS species in the inoculated plant, requiring an increase of the amount of active catalase to 
detoxify.

Thaumatin is a small protein from the PR-5 family, able to produce disruption of the plasma membrane of the pathogenic fungi. $P R-5$ genes codifying for thaumatin are differentially expressed after inoculation of sugarcane plants with $S$. scitamineum or C. falcatum [35].

\subsection{Sugarcane Omics of Defense Proteins Related To Phenylpropanoids and Lignin Biosynthesis}

Papini-Terzi et al. [36], using the cDNA microarrays technique, found three genes codifying for PAL and mainly expressed in immature internodes of sugarcane stalks, SCCCLR1048D07.g, SCEQRT1024E12.g and SCSGAM1094D05.g. One of this, SCEQRT1024E12.g was induced after ABA treatment and repressed by drought stress. In addition, other genes related to lignin biosynthesis were also found, such as P-coumaroyl shikimate 3'-hydroxylase (SCACSB1037A07.g), ferulate-5-hydroxylase (SCEZHR1087F06.g), cinnamic acid 4-hydroxylase (SCSGFL4193B05.g) and caffeic acid 3-O-methyltransferase (SCRFLR1012F12.g).

Selman-Housein et al. [37] described that sugarcane contains two genetic copies of CAD, one of which is a gene encoding for a protein that exhibits synapyl alcohol dehydrogenase activity (SAD). Although it has been repeatedly described that $\mathrm{CAD}$ can use both coniferyl and synapyl aldehydes as substrates [38]. Li et al. [39] were able to isolate a new gene from poplar that encodes for a unique synapyl alcohol dehydrogenase (SAD), different from CAD, from the same species. The existence of this second gene has been studied in the evolutionary history of the CAD family of genes in which, at least, two classes of genes for cinnamoyl alcohol dehydrogenase have been described, the class I, which is accepted as bona fide CAD, and class II, which comprises members similar to the gene for poplar synapyl alcohol dehydrogenase [10].

On the other hand, Sanchez-Elordi et al. [40] showed that in smut-resistant cv plants, such as Mayari (My) 55-14, infected with fungal sporidia, transcription of the CAD (called SofCAD) gene decreased. Quantitative RT-PCR analysis showed that the levels of expression of the SofCAD gene were higher in the resistant cultivar My 55-14 than in the sensitive cultivar B 42231 before infection. Inoculation with fungal sporidia or water decreased the level of $\operatorname{SofCAD}$ transcripts in My 55-14, indicating that regulation of SofCAD expression is not part of the specific response to the smut infection.

Jin-Long et al. [41] identified a cDNA sequence corresponding to a sugarcane gene encoding for a DIR-like protein, called in this case ScDir. Another gene for a DIRlike protein, called $S h D P 1$, was detected by nucleic acids hybridization in the area of the vascular bundles and their fibers of the rind of a young sugarcane stalk internode. Nobile et al. [12] described 13 genes, ShDIR, codifying different DIR proteins, the expression of which is low in leaves but high in mature tissues of stalks that possess lignified secondary cell walls. A gene ShDIR16 was previously identified in sugarcane plants by Damaj et al. [42] as well as its corresponding promoter, modulating its expression in stem tissues.

Sanchez-Elordi et al. [40] showed that infection by smut sporidia nullified the expression of a DIR protein specific of sugarcane, named DIR16, a protein included in the set of glycoproteins produced by the plant as a resistance response to smut. However, unlike the expression of CAD, the expression of SofDIR16 was not nullified in My 55-14 after an injection of water, equivalent to the stress produced by a mechanical injury. The authors proposed that the decrease in the expression of the leading proteins induces the formation of lignans, which participate in the defense response of the smut-resistant My 55-14 cultivar, a hypothesis that was later confirmed [43].

\subsection{Phylogenetic Relationships Among Dirigent Proteins (DIR)}

Currently, a large number of DIR genes have been described for different plant species. A family with nine DIR genes involved in coupling of E-coniferyl alcohol to produce (+)-pinoresinol has been described in Thuja plicata [44]. A previous study of phylogenetic relationships with 72 DIR and DIR-like proteins suggests five distinct subfamilies [45]. Several proteins of the clusters $\mathrm{E}$ and $\mathrm{F}$ have been previously identified as members of DIR involved in stereoselective phenolic coupling reaction in the formation of lignin and lignins. Also, these clusters (E and F) contain DIR and DIRlike proteins from different conifers species previously described by Ralph et al. [45]. The formation (+)-pinoresinol is directed by a (+)-pinoresinol-forming DIR protein in Forsythia intermedia [46-49], Arabidopsis and Schizandra although (-)-pinoresinol-forming DIR proteins (AtDIR5 and AtDIR6) have been identified in A. thaliana [50]. Other (+)pinoresinol-forming DIR proteins have also been detected in Thuja plicata (TpDIR5 and TpDIR8) and Schizandra chinensis (ScDIR) [50]. The (+)-pinoresinol-forming DIR proteins are grouped in the clusters F, E and D and are related with DIR proteins of different Pinidae species located in the cluster E. The (-)-pinoresinol-forming DIR proteins are in the cluster C. The DIR protein of S. officinarum (SofDIR16) found in our laboratory [40] might be grouped in a different cluster (cluster A) together with other DIR proteins of Poaceae species and belongs to a different subfamily of DIR proteins.

The different models of amino acid substitutions and clustering methods used to develop the trees always gave dendrograms with the same structure. The analysis involved 104 amino acid sequences of dirigent or dirigent-like proteins obtained from NCBI and Phytozome.

The dendrogram of the Figure 2 was inferred using the Neighbor-Joining clustering method [51] and the evolutionary distances were computed using the Poisson correction method [52] and they are expressed in the units of the number of amino acid substitutions per site. The tree obtained for dirigent proteins have six main clusters (Figure 2 ). The dirigent proteins of Saccharum are grouped and more 
related with the dirigent proteins of other Poaceae species. All the dirigent proteins of the Poaceae species are grouped together in the same cluster (cluster A, red lines) except eight dirigent proteins. Four Poaceae proteins of Zea mays (Zma), Sorghum bicolor (Sbi) and Oryza sativa (Osa) that are grouped with three dirigent proteins from Arabidopsis thaliana (Ath) (Cluster B, black lines). Other four Poaceae proteins of Triticum urartu (Tur), Aegilops tauschii (Ata), Setaria Italica (Sit) and Oryza sativa (Osa) are in the same cluster that proteins of $A$. thaliana (Ath), Arabidosis lyrata (Aly), Fragaria vesca (Fve), Populus trichocarpa (Ptr), Prunus persica (Pper), Brassica rapa (Bra), Capsella rubella (Cru) and Eutrema salsugineum (Esa) (Cluster C, magenta lines). In the other three clusters (D, E and F, green lines) there are not dirigent proteins from Poaceae species. The cluster E have mainly DIR proteins from conifer species (Pinaceae, Pinidaea), from Oleaceae, Salicaceae, Rosaceae and other eudycot species.

\section{E}
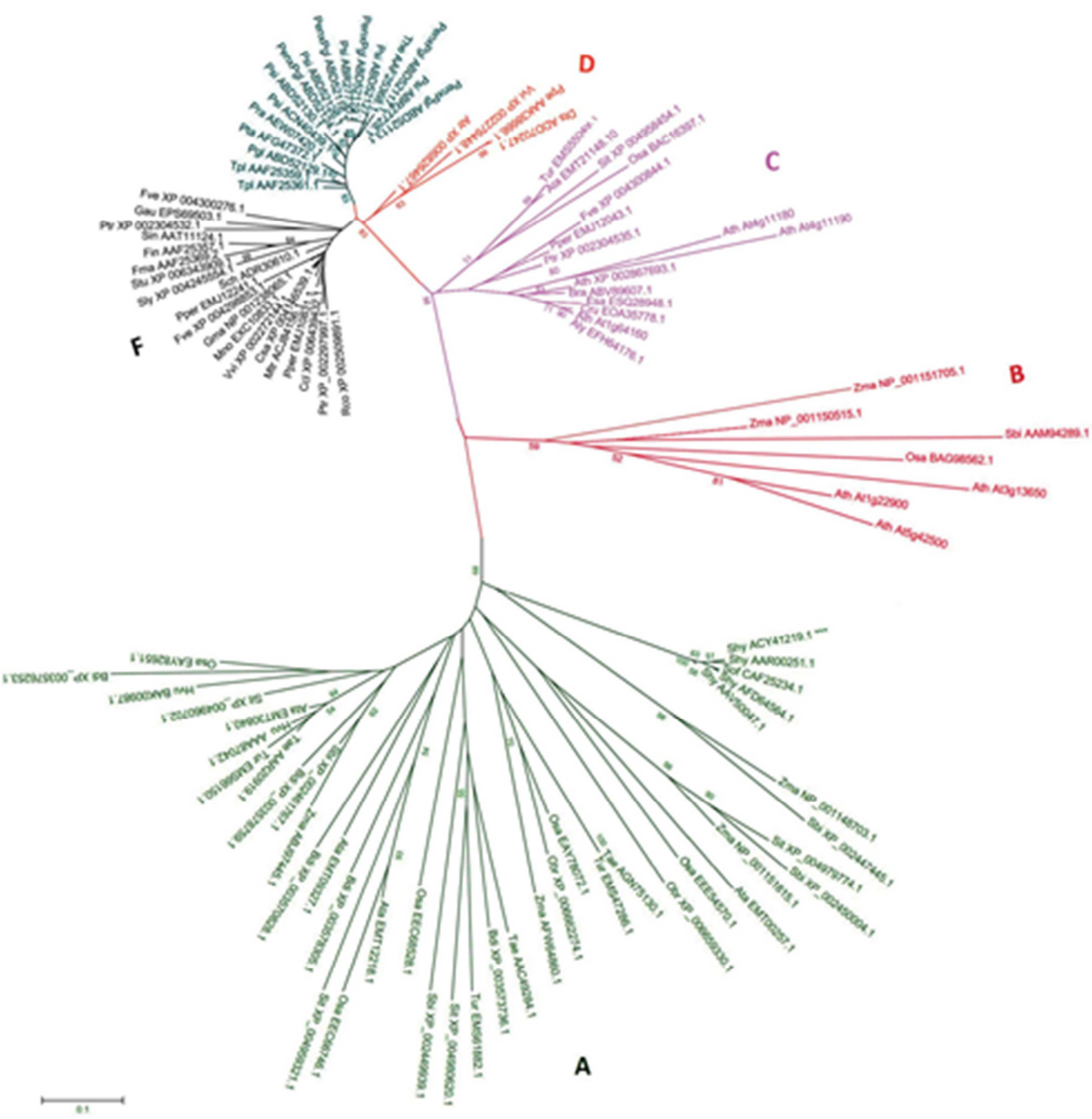

Figure 2. Dendrogram obtained with 104 DIR or like-DIR proteins from several Poaceae species and other monocots and dicots plant species, using Number of differences, Neighbour Joining and 10,000 bootstrap replicates. The sugar cane sequence used in the expression studies in this work is indicated by asterisk (Shy ACY41219.1). The amino acid sequences of these proteins were obtained from NCBI and Phytozome. Aly (Arabidopsis lyrata), Ata (Aegilops tauschii), Ath (Arabidopsis thaliana), Atr (Amborella trichopoda), Bdi (Brachypodium distachyon), Bra (Brassica rapa), Ccl (Citrus clementina), Cru (Capsella rubella), Csa (Cucumis sativus), Dts (Dysosma tsayuensis), Esa (Eutrema salsugineum), Fin (Forsythia intermedia), Fma (Fraxinus mandshurica), Fve (Fragaria vesca), Gau (Genlisea aurea), Gma (Glycine max), Hvu (Hordeum vulgare), Mno (Morus notabilis), Mtr (Medicago truncatula), Osa (Oryza sativa), Obr (Oryza brachyantha), Pen x Pgl (Picea engelmani $\times$ Pices glauca), Pgl (Picea glauca), Ppe (Podophyllum peltatum), Pper (Prunus persica), Pra (Pinus radiate), Psi (Picea sithchensis), Pta (Pinus taeda), Ptr (Populus trichocarpa), Rco (Ricinus communis), Sbi (Sorghum bicolor), Shy (Saccharum hybrid cv Pindar), Sin (Sesamun indicum), Sit (Setaria italic), Sly (Solanum lycopersicon), Sof (Saccharum officinarum), Sch (Schisandra chinensis), Stu (Solanum tuberosum), Tae (Triticum aestivum), The (Tsuga hererophylla), Tpl (Thuja plicata), Tur (Triticum urartu), and Vvi (Vitis vinifera). 


\section{Conclusion}

The sugarcane genome has been intensively studied using the most advanced techniques in Molecular Biology for more than 20 years. Today we know genes that encode for the main enzymes of the complex photosynthesis of this $\mathrm{C} 4$ plant as well as the influence that different diseases have on the expression of these genes.

Also, in a parallel way, genomics and proteomics studies are being developed regarding defense proteins against different pathogens. Elicitors produced by the invading agent can induce the expression of genes codifying proteins related to oxidative processes, proteins that hydrolyze the cell walls of the pathogen, enzymes for the synthesis of biologically active phenols, such as benzoic acids, cinnamic acids and their derivatives, including flavonoids and lignans, and enzymes from lignin synthesis. On another front, the expression of proteins that act as signalling systems has also been studied. Main attention has been paid to the socalled dirigent proteins, which are able to direct the use of monolignols towards lignan synthesis or polymerization. The dirigent proteins of sugar cane are grouped in cluster A, which includes the DIR of Poaceas, except for some of Zea mays, Sorghum bicolor and Oryza sativa, which are grouped with other three leader proteins of Arabidopsis thaliana.

\section{Acknowledgements}

This work was supported by a grant from the Ministerio de Ciencia e Innovación (Spain), BFU2009-11983 and a grant from the Complutense University GR3/14 to M. E. Legaz and C. Vicente.

\section{References}

[1] A. R. Sundar, N. M. R. Ashwin, E. L. Barnabas, P. Malathi, and R. Viswanathan, "Disease resistance in sugarcane-an overview," Sci. Agr. Paranae., vol. 4, pp. 200-212, 2015.

[2] R. Santiago, R. de Armas, M. E. Legaz, and C. Vicente, "Changes in phenolic acids content, phenylalanine ammonialyase and peroxidase activities in sugarcane leaves induced by elicitors isolated from Xanthomonas albilineans," Austral. Plant Pathol., vol. 38, pp. 357-365, 2009.

[3] B. Alarcón, R. Santiago, C. Vicente, and M. E. Legaz, "Structural changes of lignified tissues from sugarcane leaves induced by a smut (Sporisorium scitamineum) elicitor," J. Life Sci., vol. 6, pp. 287-300, 2012.

[4] A. R. Sundar, R. Viswanathan, P. Malathi, and P. Padmanaban, "Mechanism of resistance induced by plant activators against Colletotrichum falcatum in sugarcane," Arch. Phytopathol. Plant Protect., vol. 39, pp. 259-272. 2006.

[5] B. Asthir, K. Preet, S. K. Batta, and B. Sharma, "Role of antioxidative enzymes in red rot resistance in sugarcane," Sugar Tech., vol. 11, pp. 282-287, 2009.

[6] A. M. H. Esh, A. A. Guirgis, M. M. A. El-Kholi, E. A. El-
Absawy, M. I. Nasr, and E. H. Hassanien, "The activity of pathogenesis related proteins in smut resistant and susceptible sugarcane (GT54-9) mutants induced by gamma radiation," Adv. Plants Agric. Res., vol. 1, pp. 146 156, 2014.

[7] J. P. R. Marques, J. W. Hoy, B. Appezzato-da-Glória, A. F. G. Viveros, M. L. C. Vieira, and N. Baisakh, "Sugarcane cell wall-associated defense responses to infection by Sporisorium scitamineum," Front. Plant Sci., vol. 9, doi.org/10.3389/fpls.2018.00698, 2018.

[8] R. Santiago, B. Alarcón, R. de Armas, C. Vicente, and M. E. Legaz, "Changes in cinnamyl alcohol dehydrogenase activities from sugarcanre cultivars inoculated with Sporisorium scitamineum sporidia," Physiol. Plant., vol. 145, pp. 245-259, 2012.

[9] B. Alarcón, R. de Armas, C. Vicente, and M. E. Legaz, "Inhibition by substrates of a coniferyl alcohol dehydrogenase purified from sugarcane stalks," Current Enz. Inhib., vol. 15, pp. 1-9, 2019.

[10] D. M. Guo, J. H. Ran, and X. Q. Wang, "Evolution of the cinnamyl/sinapyl alcohol dehydrogenase (CAD/SAD) gene family: the emergence of real lignin is associated with the origin of bona fide CAD," J. Mol. Evol., vol. 71, pp. 202-218, 2010 .

[11] R. E. Casu, C. M. Dimmock, S. C. Chapman, C. P. L. Grof, C. L. McIntyre, G. D. Bonnett, and J. M. Manners, "Identification of differentially expressed transcripts from maturing stem of sugar cane by in silico analysis of stem expressed sequence tags and gene expression profiling," Plant Mol. Biol., vol. 54, pp. 503-517, 2004.

[12] P. M. Nobile, A. Bottcher, J. L. S. Mayer, M. S. Brito, I. A. dos Anjos, M. G. de Andrade-Landell, R. Vicentini, S., Creste,DD. M. Riaño-Pachón, and P. Mazzafera, "Identification, classification and transcriptional profiles of dirigent domaincontaining proteins in sugarcane," Mol. Genet. Genom., vol. 292, pp. 1323-1340, 2017.

[13] P. Sharma, A. B. Jha, R. S. Dubey, and M. Pessarakli, "Reactive oxygen species, oxidative damage, and antioxidative defense mechanism in plants under stressful conditions," J. Bot., vol. 2012 doi: 10.1155/2012/217037, 2012.

[14] A. R. Sundar, and P. Vidhyasekaran, "Differential induction of phenylpropanoid metabolites in suspension-cultured cells of sugarcane by fungal elicitors," Acta Phytopathol. Entomol. Hung., vol. 38, pp. 29-42, 2003.

[15] E. Sánchez-Elordi, L. Morales de los Ríos, E. M. Díaz, A., Ávila, M. E. Legaz, and C., Vicente, "Defensive glycoproteins from sugarcane plants induce chemotaxis, cytoagglutination and death of smut teliospores," J. Plant Pathol., vol. 98, pp. 493-501, 2016.

[16] Y. C. Su, L. P. Xu, B. T. Xue, Q. B. Wu, J. L. Guo, L. G., Wu, and Y. X. Que, "Molecular cloning and characterization of two pathogenesis-related beta-1,3-glucanase genes ScGluA1 and ScGluD1 from sugarcane infected by Sporisorium scitamineum," Plant Cell Rep., vol. 32, pp. 1503-1519, 2013.

[17] R. Santiago, A. M. Millanes, M. E. Legaz, and C. Vicente, "Measurement of $\beta-1,3$ glucanase activity in permeabilized discs of leaves of healthy and scald-diseased plants," J. Life Sci., vol. 6, pp. 175-181, 2012. 
[18] A. M. Millanes, B. Fontaniella, M. E. Legaz, and C. Vicente, "Glycoproteins from sugarcane plants regulate cell polarity of Ustilago scitaminea teliospores," J. Plant Physiol., vol. 162, pp. 253-265, 2005.

[19] A. M. Millanes, C. Vicente, and M. E. Legaz, "Sugarcane glycoproteins bind to surface, specific ligands and modify cytoskeleton arrangement of Ustilago scitaminea teliospores," J. Plant Interact., vol. 3, pp. 95-110, 2008.

[20] E. Sánchez-Elordi, L. Morales de los Ríos, C. Vicente, and M. E. Legaz, "Sugar cane arginase competes with the same fungal enzyme as a false quorum signal against smut teliospores," Phytochem. Lett., vol. 14, pp. 115-122, 2015.

[21] E. Sánchez-Elordi, M. Vicente-Manzanares, E. M. Díaz, M. E. Legaz, and C. Vicente, "Plant-pathogen interactions: Sugarcane glycoproteins induce chemotaxis of smut teliospores by cyclic contraction and relaxation of the cytoskeleton," South African J. Bot., vol. 105, pp. 66-78, 2016.

[22] M. Martinez, and I. Diaz, "The origin and evolution of plant cystatins and their target cysteine proteinases indicate a complex functional relationship," BMC Evol. Biol., vol. 8, pp. $198,2008$.

[23] N. F. Valadares, R. de Oliveira-Silva, I. A. Cavini, I. A. Marques, H. D. Pereira, A. Soares-Costa, F. Henrique-Silva, H. R. Kalbitzer, C. E. Munte, and R. C. Garratt, "X-Ray crystallography and NMR studies of domain-swapped canecystatin-1," FEBS J., vol. 280, pp. 1028-1038, 2013.

[24] L. Ielpi, R. O. Couso, and M. A. Dankert, "Sequential assembly and polymerization of the polyprenol-linked pentasaccharide repeating unit of the xanthan polysaccharide in Xanthomonas campestris," J. Bacteriol., vol. 175, 24902500,1993

[25] M. Blanch, C. Vicente, D. Piñón, and M. E. Legaz, "Sugarcane glycoproteins are required to the production of an active UDP-glucose dehydrogenase by Xanthomonas albilineans," Ann. Microbiol., vol. 57, pp. 217-221, 2007.

[26] Y. Blanco, M. Blanch, D. Piñón M. E. Legaz, and C. Vicente, "Antagonism of Gluconacetobacter diazotrophicus (a sugarcane endosymbiont) against Xanthomonas albilineans (pathogen) studied in alginate-immobilized sugarcane stalk tissues," J. Biosci. Bioeng., vol. 99, pp. 366-371, 2005.

[27] Y. Que, L. Xu, J. Lin, M. Ruan, M. Zhang, and R. Chen, "Differential protein expression in sugarcane during sugarcane-Sporisorium scitamineum interaction revealed by 2DE and MALDI-TOF-TOF/MS," Comp. Funct. Genom., vol. 2011, http://dx.doi.org/10. 1155/2011/989016, 2011.

[28] P. Singh, Q. Q. Song, R. K. Singh, H. B. Li, M. K. Solanki, M K. Malviya, K. K. Verma, L. T. Yang, and Y. R. Li, "Proteomic analysis of the resistance mechanisms in sugarcane during Sporisorium scitamineum infection," Int. $J$. Mol. Sci., vol. 20, 569; doi: 10.3390/ijms20030569, 2019.

[29] Y. Su, L. Xu, Z. Wang, Q. Peng, Y. Yang, Y. Chen, and Y. Que, "Comparative proteomics reveals that central metabolism changes are associated with resistance against Sporisorium scitamineum in sugarcane," BMC Genomics, vol. 17, 800, DOI 10.1186/s12864-016-3146-8, 2016.

[30] Y. Su, Z: Wang, F. Liu, Z. Li, Q. Peng, J. Guo, L. Xu, Y. Que, "Isolation and characterization of ScGluD2, a new sugarcane $\beta$-1,3-glucanase $\mathrm{D}$ family gene induced by Sporisorium scitamineum, $\mathrm{ABA}, \mathrm{H}_{2} \mathrm{O}_{2}, \mathrm{NaCl}$, and $\mathrm{CdCl}_{2}$ stresses". Front.
Plant Sci., 7, doi: 10.3389/fpls.2016.01348, 2016.

[31] S. S. Wang, Y. C. Su, Y. T. Yang, J. L. Guo, and L. P. Xu, "Molecular cloning and expression analysis of chitinase gene ScChiVII1 in sugarcane," Chin. J. Trop. Crop., vol. 35, pp. 289-298, 2014.

[32] S. Lin, Y. Zhou, G. Chen, Y. Zhang, W. Ning, and D. Pan, "Molecular responses to the fungal pathogen Gibberella fujikuroi in the leaves of chewing cane (Saccharum officinarum L.)," Sugar Tech., vol. 12, pp. 36-46, 2010.

[33] R. Viswanathan, "Molecular basis of red rot resistance in sugarcane," Funct. Plant Sci. Biotechnol., vol. 6, 40-50, 2012.

[34] Y. Que, Y. Su, J. Guo, Q. Wu, and L. Xu, "A global view of transcriptome dynamics during Sporisorium scitamineum challenge in sugarcane by RNA-Seq," PLoS One, vol. 9, e106476, 2014

[35] M. Sathyabhama, R. Viswanathan, P. Malathi, and A. R. Sundar, "Identification of differentially expressed genes in sugarcane during pathogenesis of Colletotrichum falcatum by suppression subtractive hybridization (SSH)," Sugar Tech., vol. 18, pp. 176-183, 2015.

[36] F. S. Papini-Terzi, F. R. Rocha, R. Z. N. Vêncio, J. M. Felix, D. S. Branco, A. Waclawovsky, L. E. V. Del Bem, C. G. Lembke, M. D. L Costa, M. Y. Nishiyama, R. Vicentini, M. G. A. Vincentz, E. C. Ulian, M. Menossi, and G. M. Souza, "Sugarcane genes associated with sucrose content," $B M C$ Genomics, vol. 10, 120 doi: 10.1186/1471-2164-10-120, 2009.

[37] G. Selman-Housein, M. A. López, D. Hernández, L. Civardi, F. Miranda, J. Riga, and P. Puigdomènech, "Molecular cloning of cDNA coding for three sugar cane enzymes involving in lignification," Plant Sci., vol. 143, pp. 163-171, 1999.

[38] H. J. Mitchell, J. L. Hall, and M. S. Barber, "Elicitor-induced cinnamyl alcohol dehydrogenase activity in lignifying wheat (Triticum aestivum) leaves," Plant Physiol., vol. 104, pp. 551556, 1994.

[39] L. Li, X. F. Cheng, J. Leshkevich, T. Umezawa, S. A. Harding, and V. L. Chiang, "The last step of syringyl monolignol biosynthesis in angiosperms is regulated by a novel gene encoding sinapyl alcohol dehydrogenase," The Plant Cell, vol. 13, pp. 1567-1586, 2001.

[40] E. Sánchez-Elordi, R. Contreras, R. de Armas, M. C. Benito, B. Alarcón, E. de Oliveira, C. del Mazo, E. M. Díaz-Peña, R. Santiago, C. Vicente, and M. E. Legaz, "Differential expression of SofDIR16 and SofCAD genes in smut resistant and susceptible sugar cane cultivars in response to Sporisorium scitamineum," J. Plant Physiol., vol. 226, pp. 103-113, 2018.

[41] G. Jin-Long, X. Li-Ping, F. Jing-Ping, S. Ya-Chun, F. HuaYing, Q. You-Xiong, and X. Jing-Sheng, "A novel dirigent protein gene with highly stem-specific expression from sugarcane, response to drought, salt and oxidative stresses," Plant Cell Rep., vol. 31, pp. 1801-1812, 2012.

[42] M. B. Damaj, C. KumpatlaEmani, P. D. Beremand, A. S. Reddy, K. S. Rathore, M. T. Buenrostro-Nava, I. S. Curtis, T. L. Thomas, and T. E. Mirkov, "Sugarcane dirigent and omethyltransferase promoters confer stem-regulated gene expression in diverse monocots," Planta, vol. 231, pp. 1439 $1458,2010$. 
[43] E. Sánchez-Elordi, R. M. Sterling, R. Santiago, R. de Armas, C. Vicente, and M. E. Legaz, "Increase in cytotoxic lignans production after smut infection in sugar cane plants," J. Plant Physiol., $\quad$ vol. $\quad 244, \quad 153087$, https://doi.org/10.1016/j.jplph.2019.153087, 2020.

[44] M. K. Kim, J. H. Jeon, M. Fujita, L. B. Davin, and N. G. Lewis, "The western red cedar (Thuja plicata) 8-8' DIRIGENT family displays diverse expression patterns and conserved monolignol coupling specificity," Plant Mol. Biol., vol. 49, pp. 199-214, 2002.

[45] S. G. Ralph, S. Jancsik, and J. Bohlmann, "Dirigent proteins in conifer defense. II. Extended gene discovery, phylogeny, and constitutive and stress-induced gene expression in spruce (Picea spp.)," Phytochemistry, vol. 68, pp. 1975-1991, 2007.

[46] L. B. Davin, H. B. Wang, A. L. Crowell, D. L. Bedgar, D. M. Martin, S. Sarkanen, and N. G. Lewis, "Stereoselective bimolecular phenoxy radical coupling by an auxiliary (dirigent) protein without an active center," Science, vol. 275, pp. 362366, 1997.

[47] D. R. Gang, M. A. Costa, M. Fujita, A. T. Dinkova-Kostova, H. B. Wang, V. Burlat, W. Martin, S. Sarkanen, L. B. Davin, and N. G. Lewis, "Regiochemical control of monolignol radical coupling: a new paradigm for lignin and lignan biosynthesis," Chem. Biol., vol. 6, pp. 143-151, 1999.

[48] S. C. Halls, and N. G. Lewis, "Secondary and quaternary structures of the $(+)$-pinoresinol forming dirigent protein," Biochemistry, vol. 41, pp. 9455-9461, 2002.

[49] S. C. Halls, L. B. Davin, D. M. Kramer, and N. G. Lewis, "Kinetic study of coniferyl alcohol radical binding to the (+)pinoresinol forming dirigent protein," Biochemistry, vol. 43, pp. 2587-2595, 2004.

[50] M. K. Kim, S. G. A. Moinuddin, K. M. Atwell, M. A. Costa, L. B. Davin, and N. G. Lewis, "Opposite stereoselectivities of dirigent proteins in Arabidopsis and Schizandra species," $J$. Biol. Chem., vol. 287, pp. 33957-33972, 2012.

[51] N. Saitou, and M. Nei, "The neighbor-joining method: A new method for reconstructing phylogenetic trees," Mol. Biol. Evol., vol. 4, pp. 406-425, 1987.

[52] E. Zuckerkandl, and L. Pauling, "Evolutionary divergence and convergence in proteins." In: Evolving Genes and Proteins, V. Bryson, and H. J. Vogel, Eds., Academic Press, New York, 1965, pp. 97-166. 